\title{
TIME-DEPENDENT BEHAVIOUR ANALYSIS OF LONG-SPAN CONCRETE ARCH BRIDGE
}

\author{
YONGBAO WANG ${ }^{1,2}$, RENDA ZHAO ${ }^{2 *}$, \\ YI JIA ${ }^{2}$, PING LIAO² \\ ${ }^{1}$ College of Civil Engineering, Taiyuan University of Technology, \\ Taiyuan, P.R. China \\ ${ }^{2}$ School of Civil Engineering, Southwest Jiaotong University, \\ Chengdu P.R. China
}

Received 21 September 2017; accepted 28 July 2018

\begin{abstract}
This paper continues the previous study on clarifying the timedependent behaviour of Beipanjiang Bridge - a reinforced concrete arch bridge with concrete-filled steel tubular stiffened skeleton. The obtained prediction models and the Finite Element Models were used to simulate the long-term behaviour and stress redistribution of the concrete arch bridge. Threedimensional beam elements simulated the stiffened skeleton and surrounding concrete. Then, a parameters study was carried out to analyse the timedependent behaviour of the arch bridge influenced by different concrete creep and shrinkage models. The simulation results demonstrate that concrete creep and shrinkage have a significant influence on the time-dependent behaviour of the concrete arch bridge. After the bridge completion, the Comite EuroInternational du Beton mean deviation of displacements obtained by 1990 CEBFIP Model Code: Design Code model and fib Model Code for Concrete Structures 2010 model are 3.4\%, 31.9\% larger than the results predicted by the modified fib Model Code for Concrete Structures 2010 model. The stresses between the steel and the concrete redistribute with time because of the concrete long-term
\end{abstract}

\footnotetext{
* Corresponding author. E-mail: rendazhao@swjtu.edu.cn 
effect. The steel will yield if the fib Model Code for Concrete Structures 2010 model is used in the analysis. The stresses in a different part of the surrounding concrete are non-uniformly distributed.

Keywords: analysis, concrete arch bridge, creep, deformation, finite element, time-dependent behaviour, stress.

\section{Introduction}

After the pre-stressed concrete bridge collapsed in Palau (Bažant, Hubler, \& Yu, 2011; Zhang, 2015), the time-dependent behaviour of long-span concrete box girder arch bridge with Concrete-Filled Steel Tubular (CFST) stiffened skeleton has attracted much attention of scholars (Ma, Xiang, \& Xu, 2013; Ma, Xiang, Zhao, Xu, \& Xie, 2012; Xie, 2012). The concrete creep and shrinkage are the main reasons causing the long-term deformation of the arch bridge (Geng, Wang, Ranzi, \& Wu, 2013; Yang, Cai, \& Chen, 2015) which affect the safety of the train operation in high-speed railway. In addition, the stress redistribution and long-term deformation are also complex for this type of bridge in the calculation.

Bažant, Yu, \& Li (2012) studied the Koror-Babeldaob bridge (a prestressed concrete bridge) based on the B3 (Bazant \& Murphy, 1995) and the modified B3 model. The results demonstrated that the B3 model with suitable parameters is more realistic than other models and matches well with the experimental results. In addition, Yu \& Li (2012) numerically investigated the long-term behaviour of KororBabeldaob Bridge. Hedegaard, French, \& Shield (2016), Wendner, Tong, Strauss, \& Yu (2015) and Zhang (2015) predicted the pre-stress loss and stress distribution of long span pre-stress concrete bridge using the method obtained by Bažant, Yu, \& Li (2012). For CFST bridge, the creep behaviour (Wang, Ma, Han, \& Deng, 2013; Yang, Cai, \& Chen, 2015) was studied based on the Finite Element Model (FEM) or experimental study. However, the stress redistribution and construction process of the CFST stiffened skeleton bridge studied in this paper is more complex than that of the pre-stressed bridge or CFST bridge. The construction stages also affect the time-dependent behaviour of the bridge (Yang, Cai, \& Chen, 2015). The surrounding concrete needs to be poured in consequence. However, the pouring consequence will affect the stress redistribution of different parts of the box girder. At present, there are few reports about the long-term behaviour of this type of bridge based on a finite element program. In the design phase of Beipanjiang Bridge, Xie (2012) took 1990 CEB-FIP Model Code (CEB-FIP 1992) as an example to predict the long-term deformation of this type of concrete arch bridge. 
Moreover, after finished construction about ten years, the deformation of the arch crown is $0.596 \mathrm{~m}$. Ma, Xiang, Zhao, Xu, \& Xie (2012) and Ma, Xiang, \& Xu (2013) studied the arch bridge by a stochastic method. However, all the calculated results are based on the creep models suitable for standard strength concrete.

The time-dependent behaviour analysis of a concrete arch bridge is few reported in the literature from an experimental aspect. This task is pursued in computational programs for long-time creep behaviour analysis of Beipanjiang Bridge. The steel tube and core concrete are simplified as beam element with the same nodes. Moreover, the surrounding concrete section is divided into six parts to simulate the construction process. The concrete creep and shrinkage models developed by the experimental study in the previous analysis (Wang, Zhao, Jia, \& Liao, 2019) are used in this bridge. The time-dependent behaviour of Beipanjiang Bridge was simulated throughout the construction phase and 100 years after construction by the FEM. At last, the calculated results were compared with different predictions by various prediction models.

\section{Long-term behaviour of the arch bridge}

\subsection{General description of the bridge}

Beipanjiang Bridge, which comes across Beipanjiang River, is located in Qinglong County in Guizhou Province of China. It is in a typical deep mountain canyon terrain of $\mathrm{V}$ shape with hard rocks, as shown in Figure 1. An arch bridge is more appropriate for this deep valley. However, the full supporting method is unsuitable for this location. Therefore, a CFST stiffened skeleton construction method was explored to pour the surrounding concrete of the box girder (Xie, 2012).

It is one of the most important bridges in the high-speed railway from Shanghai to Kunming. Long-term deformation of which is the main factor controlling the design of this bridge. As the authors know, in the construction stage, it seems that the bridge deformation was affected by shrinkage and creep effect, but this deflection was traced by adjusting the elevation of the pier on the arch. However, when the bridge is finished, the long-term deformation is unrecoverable, which affects the safety of the train operation (Geng, Wang, Ranzi, \& Wu, 2013). So, the time-dependent behaviour of the arch is needed to be further investigated by FEM in this paper.

The bridge is composed of CFST stiffened skeleton and surrounding concrete. The stiffened skeleton is taken as the construction platform,
Time-Dependent Behaviour Analysis of Long-Span Concrete Arch Bridge 


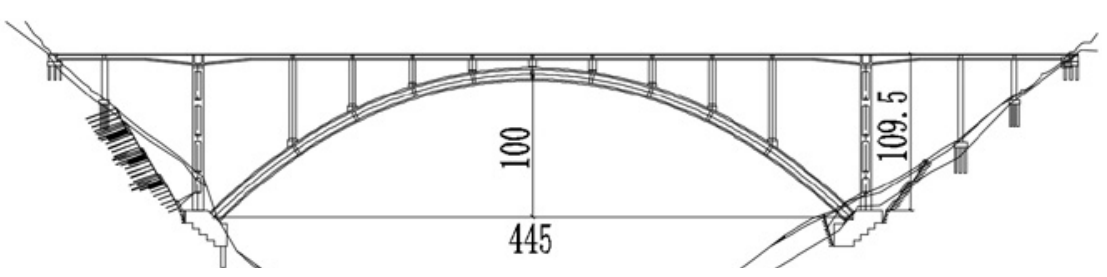

Note: units in $\mathrm{m}$.

Figure 1. Elevation view of Beipanjiang Bridge

and the surrounding concrete was poured based on the platform (Wang, Zhan, \& Zhao, 2016). The core and surrounding concrete whose properties used in this bridge was C80 and C60 concrete, respectively (Wang, Zhan, \& Zhao, 2016). The main span of the arch is $445 \mathrm{~m}$, and the rise is $100 \mathrm{~m}$, so that rise to span ratio is $1 / 4.45$. The bridge shape is a catenary line, and arch axis coefficient is 1.6. The arch section width is various ranging from $28 \mathrm{~m}$ to $20 \mathrm{~m}$ at $65 \mathrm{~m}$ in the distance of the arch springing; the section width is $20 \mathrm{~m}$ in the remaining $315 \mathrm{~m}$ of the arch. In addition, the height of the cross section is $9 \mathrm{~m}$.

A profile view of the Beipanjiang Bridge, indicating span labels are shown in Figure 1. It is noted that two-span $65 \mathrm{~m}$ rigid frame pre-stressed beam + eight-span $42 \mathrm{~m}$ pre-stressed continuous beam + two-span $65 \mathrm{~m}$ rigid frame pre-stressed beam was located on the arch rib. Figures $2 a$ and

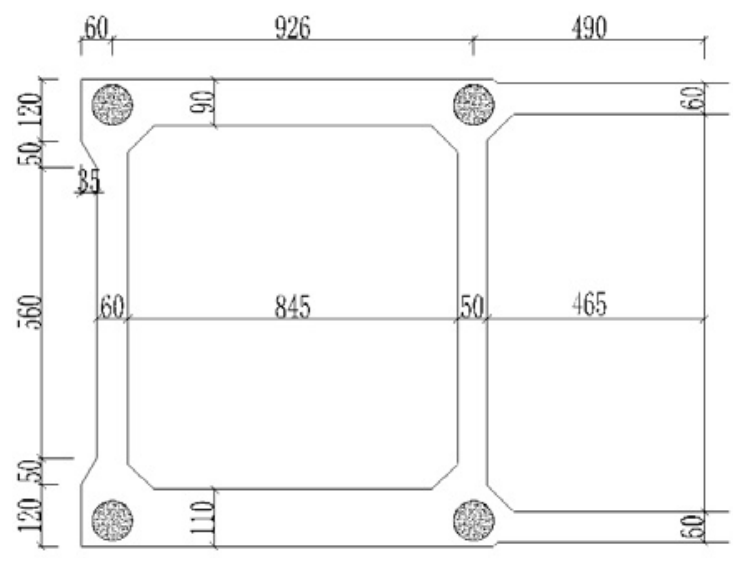

a) arch springing

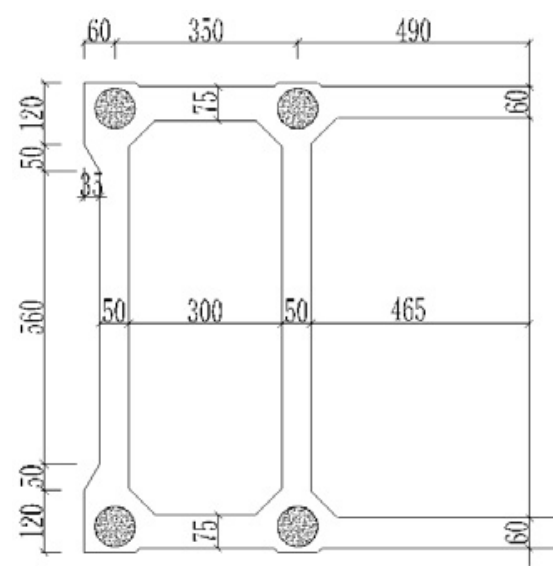

b) arch crown

Note: units in $\mathrm{cm}$.

Figure 2. Cross sections at arch springing and arch crown of Beipanjiang Bridge 
$2 \mathrm{~b}$ are the cross sections in arch springing and crown, respectively. The Behaviour Analysis diameter of the steel tube is $75 \mathrm{~cm}$. The arch is a single box girder with three cells. The top and bottom plate in the middle cell is $60 \mathrm{~cm}$. At arch crown, the thickness of the middle and side box web is $50 \mathrm{~cm}$, and the top and bottom plate in the side cell is $75 \mathrm{~cm}$. At arch springing, the thickness of the middle and side box web is $50 \mathrm{~cm}$ and $60 \mathrm{~cm}$, and the top and bottom plate in the side cell is $90 \mathrm{~cm}$ and $110 \mathrm{~cm}$, respectively.

\subsection{Finite Element Model}

\subsubsection{Element type and mesh}

A suitable commercial finite element program MADIS/Civil developed the FEM of Beipanjiang Bridge. BEAM element simulated the steel tube, pier, core concrete and surrounding concrete. In addition, the inhaul cable was simulated by LINK element. The threedimensional (3D) FEM of the Beipanjiang Bridge is shown in Figure 3. The authors simulated the concrete filled steel tube as two beam elements with same nodes because the core concrete and steel tube have the same deformation. In addition, the surrounding concrete was coupled with the CFST as an affiliated part. The rigid constraints were used to combine the stiffened skeleton and the surrounding concrete. The skewbacks, including the foundations of this bridge, were quite stiff. Thus, the skewbacks were ignored in the FEM. Moreover, the degrees of freedom associated with those nodes were fully restrained. An overview of the core concrete, stiffened skeleton, concrete crosssection and box girder are shown in Figure 4. The pouring sequences of core concrete and surrounding concrete are also plotted in

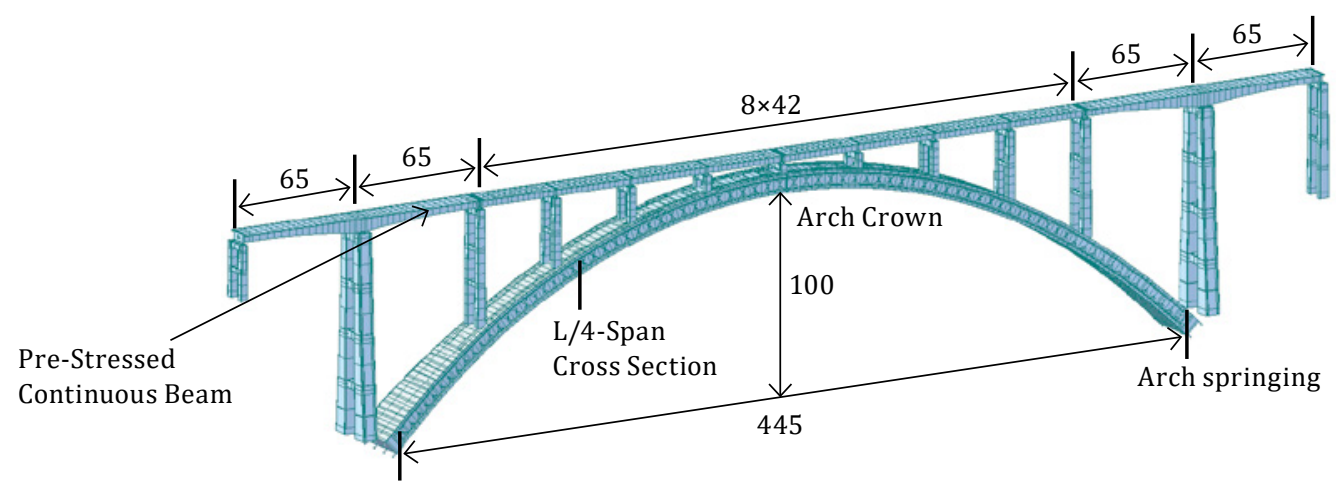

Note: units in $\mathrm{m}$.

Figure 3. 3D view of the Finite Element Model of Beipanjiang Bridge 

(2)
(4)

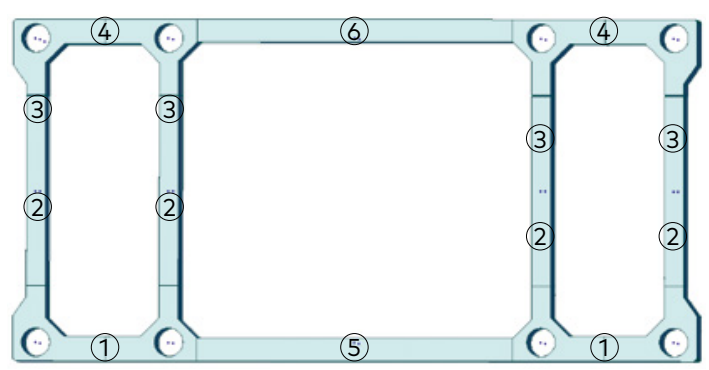

c) cross-section of the surrounding concrete

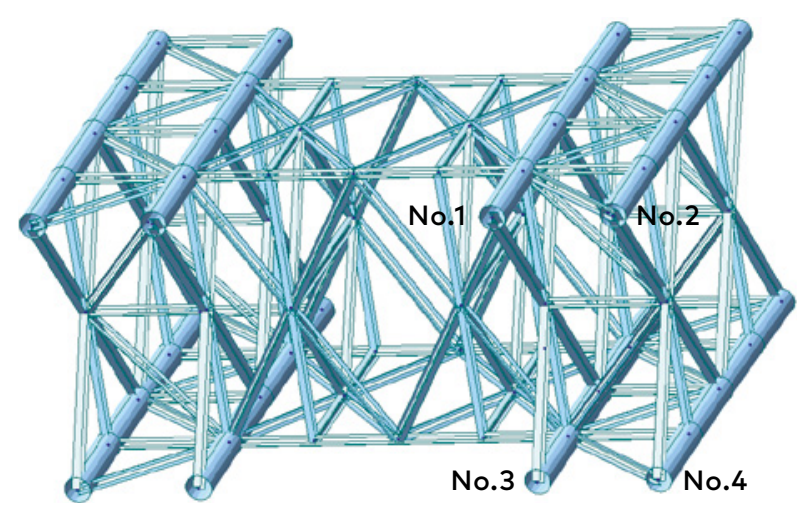

b) stiffened skeleton

Middle Box Web

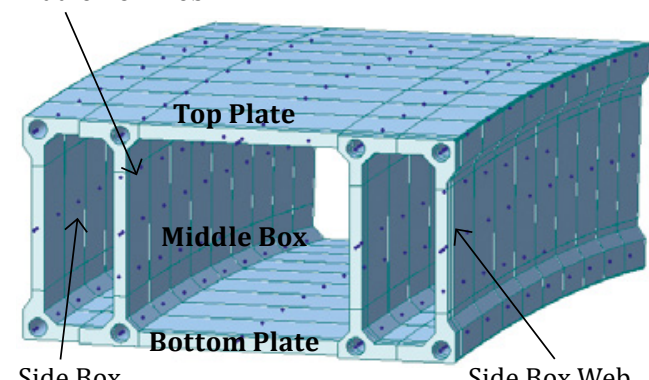

Side Box

Side Box Web

d) details of the surrounding concrete

Note: the (1), (2), ..., (6) denotes the construction sequence; and No.1, No.2, No.3, No.4 denotes the number of the arch rib.

Figure 4. Finite element components of the arch bridge

Figures 4a and 4c. Unprestressed steel reinforcement was ignored in calculations.

\subsubsection{Boundary conditions and construction process}

The bridge is a fixed arch bridge, and the specific boundary conditions are fixed on both arch springings. In addition, there are also fixed constraints between the stay cable and mountain.

There are eight steel tubes in the stiffened skeleton, as shown in Figure $4 \mathrm{~b}$. At the beginning of pouring the core or surrounding concrete, the concrete was regarded as uniform loads acting on the stiffened skeleton, because the concrete has lower compressive 
strength. Three days after the concrete had been poured, the strength of concrete reached to the design strength. So, those concrete elements were activated and combined with working with the stiffened skeleton. Different parts of steel tube, core concrete and surrounding concrete were classified into several structure groups. In different construction stages, the structure groups were activated or deactivated to simulate the construction stages. By defining the creep coefficient and shrinkage strain, the shrinkage and creep effect is calculated automatically by the software. The systematic method (Yang, Cai, \& Chen, 2015) was used for the creep analysis. The shrinkage starting age is assumed for 3 days. The thermal load was ignored in this analysis.

In the FEM, the bridge construction procedure was divided into 253 steps. The main construction steps of the arch bridge are as follows:

1. Established the arch stiffed skeleton, as shown in Figure 4b;

2. Filled steel tube with C80 concrete, the pouring sequence is shown in Figure 4a;

3. Pouring the lower half part section of the side box, as shown part (1) and (2) in Figure 4c;

4. Pouring the upper half part section of the side box, as shown part (3) and (4) in Figure 4c;

5. Pouring bottom plate part of the middle box girder, as shown part (5) in Figure 4c;

6. Pouring top plate of the middle box girder, as shown part (6) in Figure 4c;

7. Build the pre-stressed continuous beam above the arch in Figure 3;

8. The whole bridge was formed;

9. Calculating the long-term behaviour of the bridge in 100 years.

\subsubsection{Material properties}

The material parameters used in the Finite Element Model are listed in Table 1 . The concrete strength and elastic modulus were tested by the concrete prism with the size of $100 \times 100 \times 300 \mathrm{~mm}$ at 28 days, as shown in Table 2 from Wang, Zhao, Jia, \& Liao (2019). Moreover, the elastic modulus development curves with time are the fitted equation shown in Table 2 of Wang, Zhao, Jia, \& Liao (2019). As the authors know that the core concrete was sealed in steel tube without humidity exchanging with the natural environment, so the relative humidity was assumed as $90 \%$ for simplicity (Yang, Cai, \& Chen, 2015). The relative humidity of the surrounding concrete listed in Table 1 was the average relative humidity shown in Figure 5 from Wang, Zhao, Jia, \& Liao (2019). The Poisson ratio 
Table 1. Summaries of material properties used in Finite Element Model

\begin{tabular}{|c|c|c|c|c|c|c|c|}
\hline \multirow[t]{2}{*}{ Parameters } & Strength & $\begin{array}{l}\text { Elastic } \\
\text { modulus }\end{array}$ & \multirow{2}{*}{$\begin{array}{c}\text { Poisson } \\
\text { ratio }\end{array}$} & $\begin{array}{c}\text { Relative } \\
\text { humidity, }\end{array}$ & Density, & \multirow{2}{*}{$\begin{array}{l}\text { Shrinkage } \\
\text { model }\end{array}$} & \multirow[t]{2}{*}{$\begin{array}{l}\text { Creep } \\
\text { model }\end{array}$} \\
\hline & \multicolumn{2}{|c|}{ at 28 days, $\mathrm{MPa}$} & & $\%$ & $\mathrm{~kg} \cdot \mathrm{m}^{-3}$ & & \\
\hline $\mathrm{C} 80$ & 65.7 & $4.24 \cdot 10^{4}$ & 0.2 & 90.0 & 2582 & Eq. (5) & Eq. (6) \\
\hline $\mathrm{C} 60$ & 50.7 & $4.27 \cdot 10^{4}$ & 0.2 & 65.7 & 2582 & Eq. (3) & Eq. (4) \\
\hline Steel Tube & 370.0 & $2.06 \cdot 10^{5}$ & 0.3 & - & 9073 & - & - \\
\hline
\end{tabular}

Note: the numbers of Eqs (3)-(6) come from Wang, Zhao, Jia, \& Liao (2019).

of steel tube and concrete was assumed to 0.3 and 0.2 . Besides, the modified shrinkage and creep models (Eqs. (3)-(6) developed by Wang, Zhao, Jia, \& Liao (2019)) are the long-term deformation models used in this calculation.

\subsection{Long-term deformation}

Because of the space limitations, only the following representative results are included:

a) vertical deflections at the arch crown and L/4-span section of the arch (negative value represents downward);

b) stresses of the steel tube and core concrete in No. 1 and No. 4 as shown in Figure $4 \mathrm{~b}$ at the arch crown and L/4-span section of the arch (negative value represents compression);

c) the stress of the surrounding concrete in the bottom plate of the side box, the web of side box, the top plate of the middlebox in L/4span section.

The first stage of this analysis is the closure of the CFST stiffened skeleton. The arch crown and L/4-span section have larger vertical deformation than other sections, so the creep deformation curves of these two sections are shown in Figure 5. It is seen from Figure 5 that the shrinkage and creep effect during the construction and the finished stage has a large effect on the deformation of the bridge. The deformation of the arch crown is greater than L/4-span section. In addition, it increases with time due to the concrete creep and shrinkage, although they have the same deformation patterns. The nonrecoverable deformation causes a serious impact on the safety of highspeed railway operation (Ma, Xiang, Zhao, Xu, \& Xie, 2012). It is seen that after bridge completion, the deformations of the arch crown and 


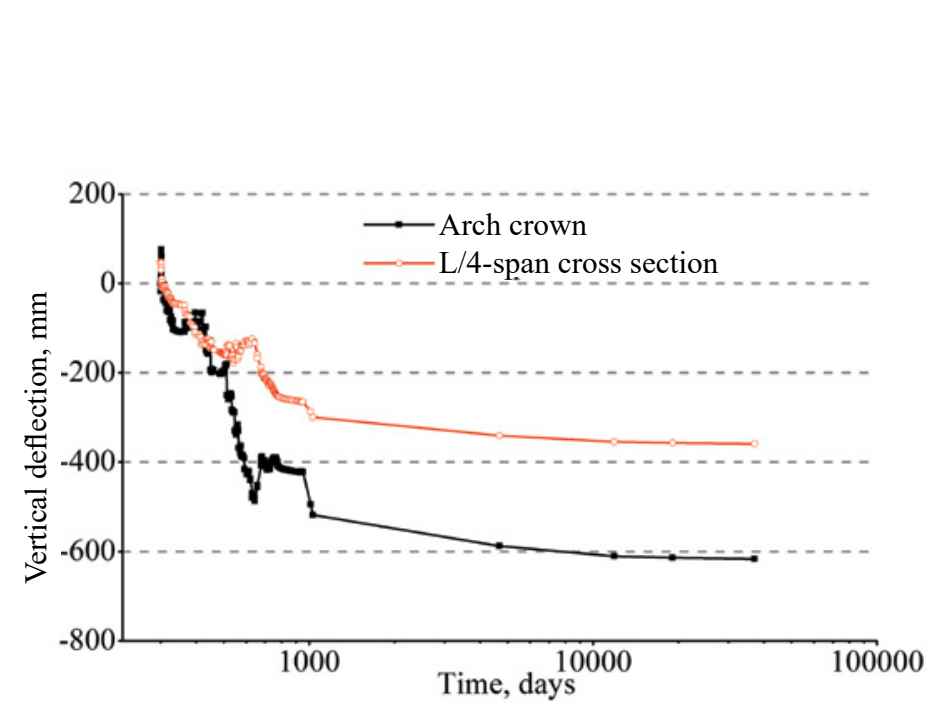

Figure 5. Deflections of concrete arch

L/4-span section are $-616 \mathrm{~mm}$ and $-359 \mathrm{~mm}$, respectively. Ten years after bridge completion, the deformation of the arch crown is $-69 \mathrm{~mm}$ compared with the deformation of the arch rib. This deformation is larger than $-59.6 \mathrm{~mm}$ calculated by Xie (2012) and smaller than $-80 \mathrm{~mm}$ developed by Ma, Xiang, Zhao, Xu, \& Xie (2012) compared by using absolute values. The ratios of the long-term deflections of the arch crown and L/4-span section after construction about 100 years to the cumulative elastic deflections are about $19.0 \%$ and $19.8 \%$, respectively.

\subsection{Stress distribution}

\subsubsection{Stress in steel tube}

Figure 6 gives the stress curves of steel tube at the arch crown and L/4-span section. It is seen from Figure 6 that the stresses of steel tube in the arch crown and L/4-span section increase with the development of construction stages, and reach to $-296.0 \mathrm{MPa}$ and $-332.0 \mathrm{MPa}$, respectively after the bridge was finished. Due to the shrinkage and creep effect, the stresses between the steel tube and core concrete are redistributed. The stress in the upper and bottom chords of the steel tubes increases with time, while, the stress of core concrete has the opposite trend. The stress of steel tubes in bottom chords is larger than upper chords. The stress increments in the arch crown and L/4-span section is $-34.0 \mathrm{MPa}$ and $-39.0 \mathrm{MPa}$ after the bridge was finished 100 years, respectively. 


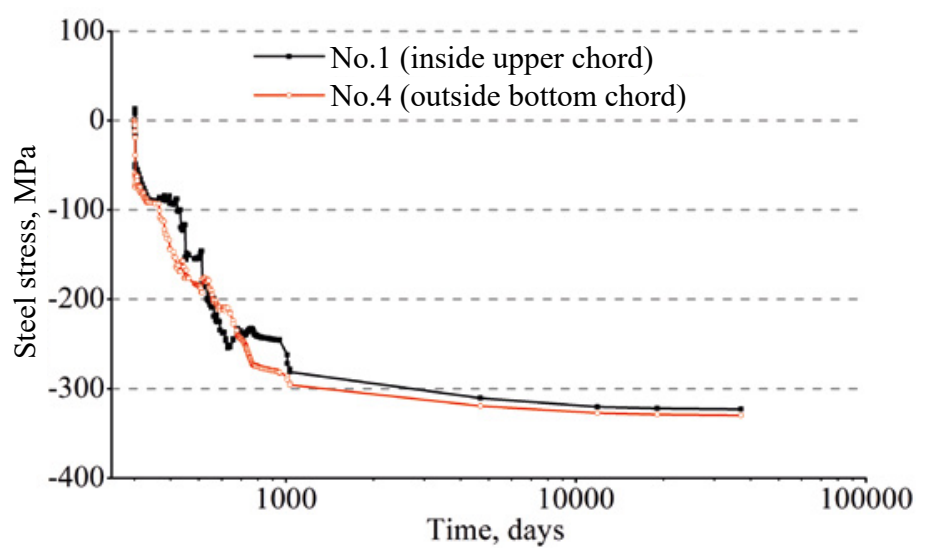

a) arch crown

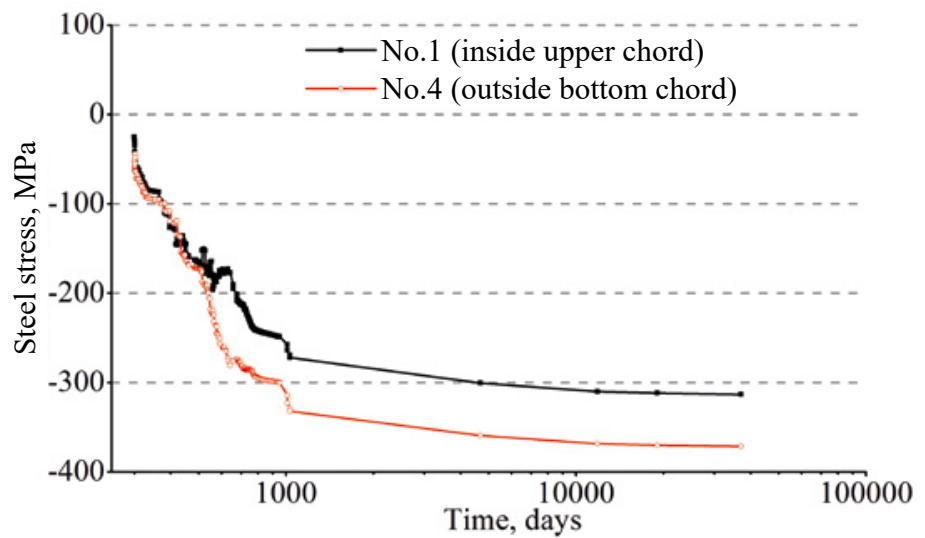

b) L/4-span cross section

Figure 6. Stresses of steel tube

\subsubsection{Stress in core concrete}

Figure 7 lists the stresses of core concrete in the arch crown and $\mathrm{L} / 4$-span section. The location of the core concrete is shown in Figure $4 \mathrm{~b}$. Because of the structure symmetry, only the analysis curves for chords of No. 1 and No. 4 are shown. All the results showed that the stress of core concrete decreases gradually over time after the bridge was finished. The stress in the two chords of the arch crown has nearly the same value. Moreover, the stress of the bottom chord is greater than the upper chord in L/4-span section. The maximum stress in core concrete is $-27.38 \mathrm{MPa}$, 


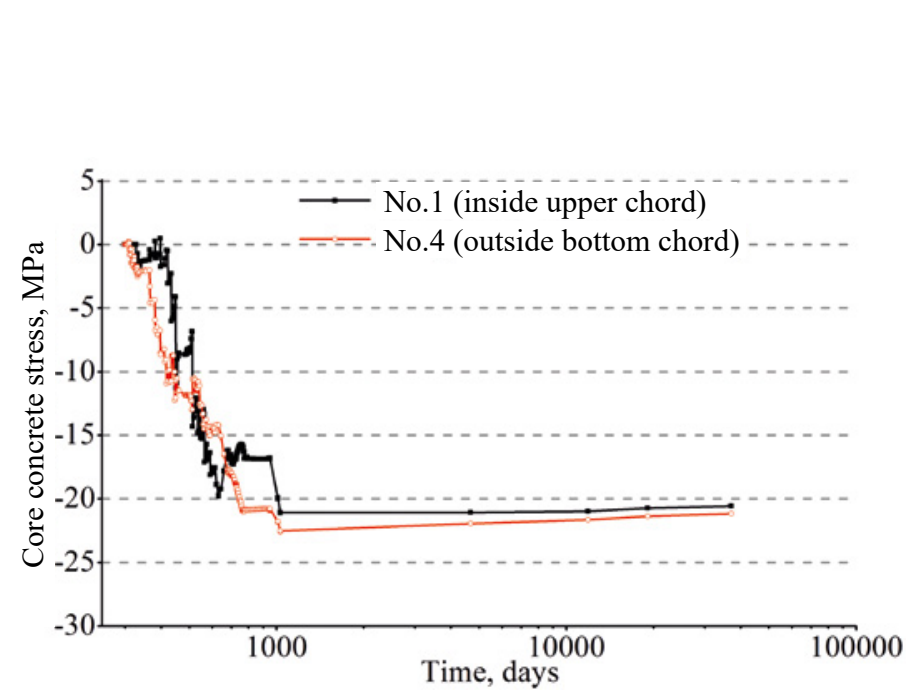

a) arch crown

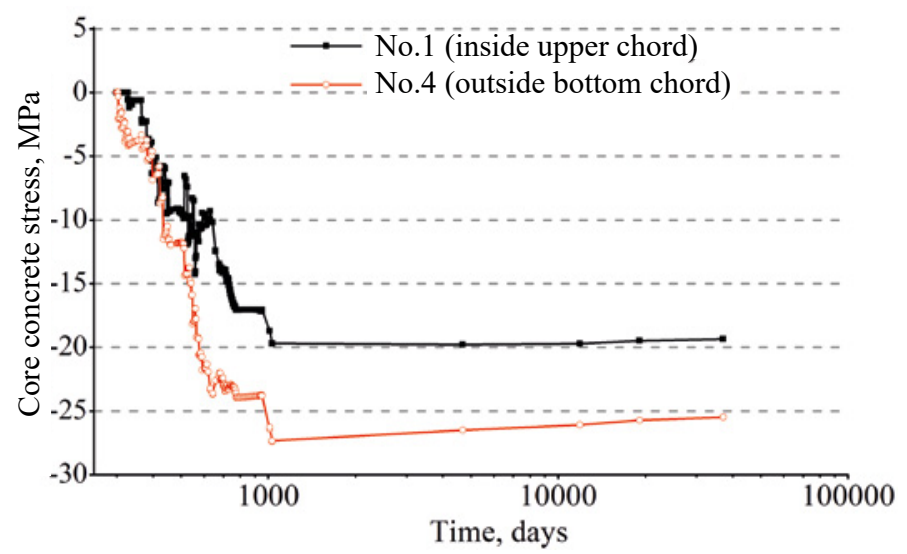

b) L/4-span cross section

Figure 7. Stresses of core concrete

which is much less than the strength of C80 concrete. The stress of core concrete in No. 4 of L/4-span section decreased from $-27.38 \mathrm{MPa}$ to $-25.48 \mathrm{MPa}$ after the bridge was finished 100 years. It has the maximum stress increment $1.90 \mathrm{MPa}$, about $7.0 \%$ of the maximum stress. In outside bottom chord (No. 4 as shown in Figure 4b), the stress increment in the arch crown is the same as the stress increment $(1.39 \mathrm{MPa})$ in $\mathrm{L} / 4$-span section. The concrete creep and shrinkage have little effect on the stress of core concrete. It means that the core concrete stress is the uncontrolled factor in the bridge design stage. 


\subsubsection{Stress in the surrounding concrete}

In Figure 8, the stresses of surrounding concrete at $\mathrm{L} / 4$-span section are illustrated. Because the L/4-span section has larger stresses compared with other sections, so the results of concrete stress in the bottom plate of side box, the web of middle box, and top plate of the middlebox in L/4-span section (the location of different plates are shown in Figure 4d) are presented. From Figure 8, the following conclusions are drawn:

1. The concrete stresses in a different part of the box-girder are affected by the bridge construction sequence. Moreover, the distribution of concrete stress is non-uniformly distributed in a different part of the box-girder. The concrete of the bottom plate located in the middle box was first poured and was also the first part to resist external load, so they have the maximum stress in a finished state. Because the top plate of middlebox girder is the last poured part, hence they have the minimum stress;

2. In the construction stage, by the influence of external load, the stresses of the surrounding concrete increase;

3. The stress in the bottom plate of the side box decreases from -12.6 MPa to - 11.7 MPa after ten years of bridge finished construction. The reduction is $0.9 \mathrm{MPa}$. Concrete stress in a web of side box also decreases with time; The maximum compressive stress increases about $0.66 \mathrm{MPa} 100$ years of the bridge are finished construction. However, the stress in the top plate of middle box increases gradually with time. Moreover, the increment is $-0.52 \mathrm{MPa}$ after 100 years.

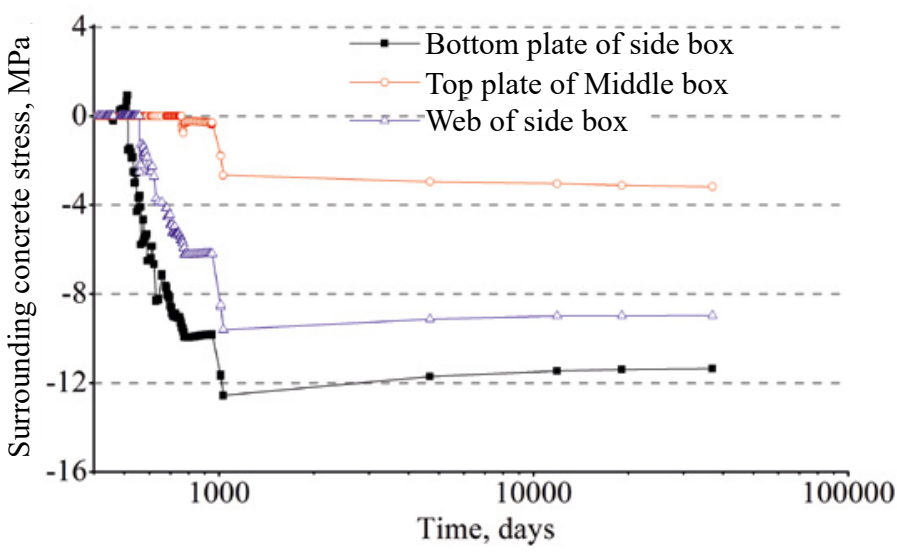

Figure 8. Stresses of surrounding concrete in L/4-span cross section 


\section{Influence of concrete creep and shrinkage models}

There are many concrete creep and shrinkage models at present, such as ACI209 (ACI209 R-92,1992), CEB90 (CEB, 1993), CEB10 model (CEB, 2012). However, each model has its limitations. The results predicted by the models, either overestimate or underestimate the experimental data in some cases (Al-Manaseer \& Prado, 2015; Goel, Kumar, \& Paul, 2007). Although the comparisons between the predicted results obtained by different shrinkage and creep prediction models and experimental results are explored by Wang, Zhao, Jia, \& Liao, (2019). The deflection differences in arch crown calculated by difference shrinkage and creep models are clear if the finite element analysis of concrete arch bridge will be carried out (Yang, Cai, \& Chen, 2015). Therefore, this study used the CEB mean deviation method (Al-Manaseer \& Prado, 2015) to evaluate the validity of the Modified CEB10 (Wang, Zhao, Jia, \& Liao, 2019), ACI209 (ACI209 $R$-92,1992), CEB90 (CEB, 1993) and CEB10(CEB, 2012) models in predicting the time-dependent behaviour of the concrete arch bridge. The CEB mean deviation $M_{\text {СЕв }}$ (as shown in Eq.) is calculated for the following ranges: 0 days to 1031 days (construction bridge stage), 1032 days to 37081 days (completed bridge stages). For simplification, Stage A means after the bridge is finished in 0 years. Stage B means after the bridge is finished 100 years in the following sections.

$$
M_{C E B}=\frac{1}{n} \sum_{j=1}^{n} \frac{Y_{j}}{y_{j}},
$$

where $y_{\mathrm{j}}$ - the calculated displacement or stress by elastic method at time $j ; Y_{j}$ - the predicted displacement or stress by modified CEB10(Wang, Zhao, Jia, \& \& Liao, 2019), ACI209(ACI209 R-92,1992), CEB90 (CEB, 1993) or CEB10 model (CEB, 2012); $M_{\mathrm{CEB}}$ - the mean deviation; $n$ - total number of datasets considered.

Based on the above models, Table 2 presents a comparison of arch crown deflection calculated by different prediction models. It is observed that the range of vertical deformation of the arch crown is $-69.46 \mathrm{~mm}$ and $-98.55 \mathrm{~mm}$ after the bridge is finished ten years and 100 years when the modified CEB10 model (Wang, Zhao, Jia, \& Liao, 2019) is considered. Each prediction model has different deflection. Ten years after the bridge was finished, the ACI209 model (ACI209 R-92,1992) provides the minimum deformation increment of $-38.94 \mathrm{~mm}$. The CEB10 model (CEB, 2012) appears to provide the largest deformation increment, which is nearly 1.74 times more than the results calculated by modified CEB10 model (Wang, Zhao, Jia, \& Liao, 2019). One hundred years after the bridge was finished, all predicted deformations are greater than $20 \mathrm{~mm}$, which is dissatisfied with the requirements of Chinese Code Technical Specification 
Table 2. Deflections of concrete arch crown for different creep models

\begin{tabular}{lccc}
\hline \multirow{2}{*}{$\begin{array}{c}\text { Prediction } \\
\text { model }\end{array}$} & $\begin{array}{c}\text { Total deflection } \\
\text { when the bridge was finished }\end{array}$ & \multicolumn{1}{c}{ 10 years } & 100 years \\
\cline { 3 - 4 } Modified CEB10 model & -616.80 & -69.46 & -98.55 \\
ACI209 model & -547.44 & -33.76 & -38.94 \\
CEB90 model & -511.35 & -89.01 & -146.95 \\
CEB10 model & -652.46 & -121.62 & -171.47 \\
\hline
\end{tabular}

Note: units in $\mathrm{mm}$.

for high-speed railway. If the results calculated by the modified CEB10 model (Wang, Zhao, Jia, \& Liao, 2019) were considered as the best values, the traditional prediction models expect ACI209 model (ACI209 R-92, 1992) overestimates the vertical deflection of the arch. The 100-year deflections considering the shrinkage and creep effect are 79-151\% larger than elastic deflection in the arch crown.

Figure 9 is plotted to describe the total vertical deflections of arch rib calculated by different prediction models. Moreover, the $M_{\text {CEB }}$ results are shown in Table 3 . If the concrete shrinkage and creep effect is considered, the vertical displacements of the arch crown and L/4-span cross section are $-617 \mathrm{~mm}$ and $-300 \mathrm{~mm}$ (Modified CEB10 model). Moreover, its average value is 1.3787 and 1.3876 times than the deflection of linear elastic analysis in Stage A. On the other hand, the deflections calculated by CEB10 model (CEB, 2012), CEB90 model (CEB, 1993) is $-171 \mathrm{~mm}$ and $-147 \mathrm{~mm}$ in Stage B, which are significantly higher than the value $-99 \mathrm{~mm}$ calculated by modified CEB10 model (Wang, Zhao, Jia, \& Liao, 2019). Results indicate that in Stage B, the ACI209 model (ACI209 R-92,1992) has the minimum values, followed by modified CEB10 model (Wang, Zhao, Jia, \& Liao, 2019), CEB90 model (CEB, 1993). The CEB10 model (CEB, 2012) ranked fourth. The maximum $M_{\text {CEB }}$ error between ACI209 (ACI209 R-92, 1992) and CEB10 model (CEB, 2012 ) is $34.7 \%$. A suitable prediction model is critical to estimate the time-dependent behaviour of the arch bridge.

Table 3. Comparison of $M_{\mathrm{CEB}}$ results of the vertical deflection

\begin{tabular}{lcccccccc}
\hline \multicolumn{1}{c}{ Location } & \multicolumn{3}{c}{ Arch crown } & \multicolumn{3}{c}{ L/4-span cross section } \\
\hline \multicolumn{1}{c}{ Models } & $\begin{array}{c}\text { Modified } \\
\text { CEB10 }\end{array}$ & ACI209 & CEB90 & CEB10 & $\begin{array}{c}\text { Modified } \\
\text { CEB10 }\end{array}$ & ACI209 & CEB90 & CEB10 \\
\hline $\begin{array}{l}M_{\text {CEB }} \text { in O days } \\
\text { to 1031 days }\end{array}$ & 1.3787 & 1.4813 & 1.3909 & 1.6737 & 1.3876 & 1.4696 & 1.3355 & 1.6648 \\
$\begin{array}{l}M_{\text {CEB }} \text { in 1032 days } \\
\text { to 37 081 days }\end{array}$ & 1.7984 & 1.7602 & 1.8596 & 2.3714 & 1.8212 & 1.7569 & 1.8187 & 2.3983 \\
\hline
\end{tabular}




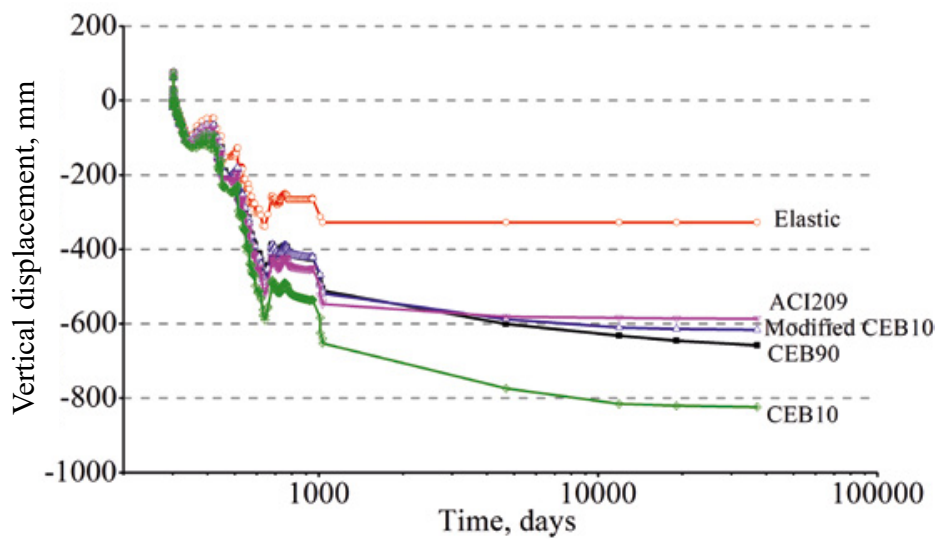

Time-Dependent Behaviour Analysis of Long-Span Concrete Arch Bridge

a) arch crown

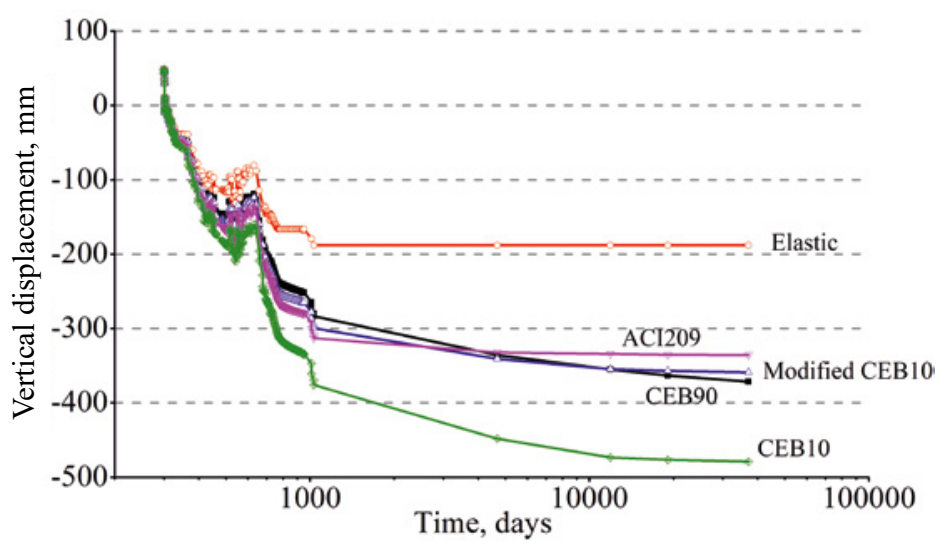

b) L/4-span cross section

Figure 9. Vertical deflection

The steel stresses predicted by different models in No. 4 of the arch crown and L/4-span section during construction stages and 100 years after the finished state are illustrated in Figure 10. In Stage A, the steel stress without considering shrinkage and creep effect of arch crown and L/4-span section is $-221 \mathrm{MPa}$ and $-243 \mathrm{MPa}$, which is less than the results $-296 \mathrm{MPa}$ and $-332 \mathrm{MPa}$ calculated by modified CEB10 model (Wang, Zhao, Jia, \& Liao, 2019), respectively. The steel stress predicted by CEB10 model (CEB, 2012) is $-400 \mathrm{MPa}$ and $-452 \mathrm{MPa}$ for arch crown and L/4-span section in Stage B. However, the stress simulates by modified CEB10 model (Wang, Zhao, Jia, \& Liao, 2019) is $-330 \mathrm{MPa}$ and $-371 \mathrm{MPa}$, respectively. All these indicate that the steel will yield because of concrete creep and shrinkage, which affect the safety of the arch. These models also predict the 100-year 
Table 4. Comparison of $M_{\mathrm{CEB}}$ results of stresses in steel tube

\begin{tabular}{lcccccccc}
\hline \multicolumn{1}{c}{ Location } & \multicolumn{3}{c}{ Arch crown } & \multicolumn{4}{c}{ L/4-span cross section } \\
\hline \multicolumn{1}{c}{ Models } & $\begin{array}{c}\text { Modified } \\
\text { CEB10 }\end{array}$ & ACI209 & CEB90 & CEB10 & $\begin{array}{c}\text { Modified } \\
\text { CEB10 }\end{array}$ & ACI209 & CEB90 & CEB10 \\
\hline $\begin{array}{l}M_{\text {CEB }} \text { in O days } \\
\text { to 1031 days }\end{array}$ & 1.1836 & 1.2192 & 1.1613 & 1.2952 & 1.2012 & 1.2523 & 1.1915 & 1.3240 \\
$\begin{array}{l}M_{\text {CEB }} \text { in 1032 days } \\
\text { to 37 081 days }\end{array}$ & 1.4464 & 1.4336 & 1.4551 & 1.7328 & 1.4804 & 1.4841 & 1.5004 & 1.7827 \\
\hline
\end{tabular}

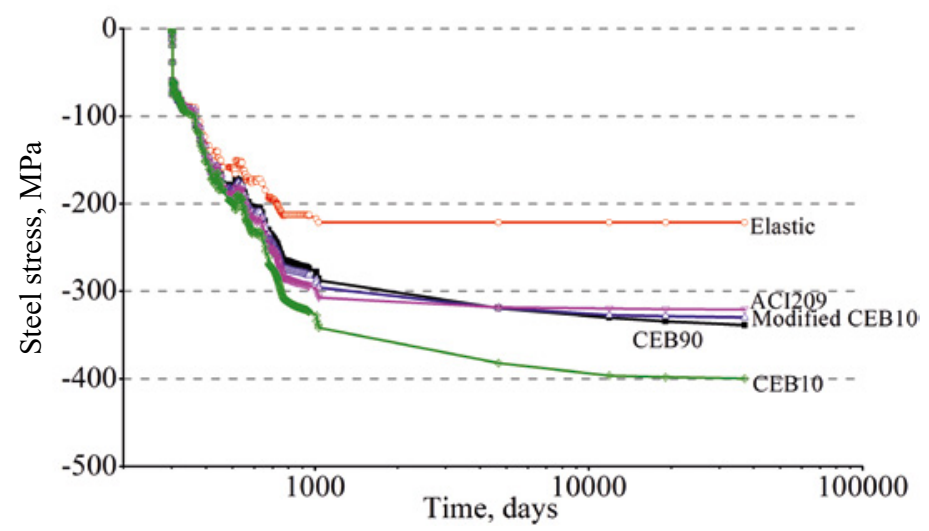

a) arch crown

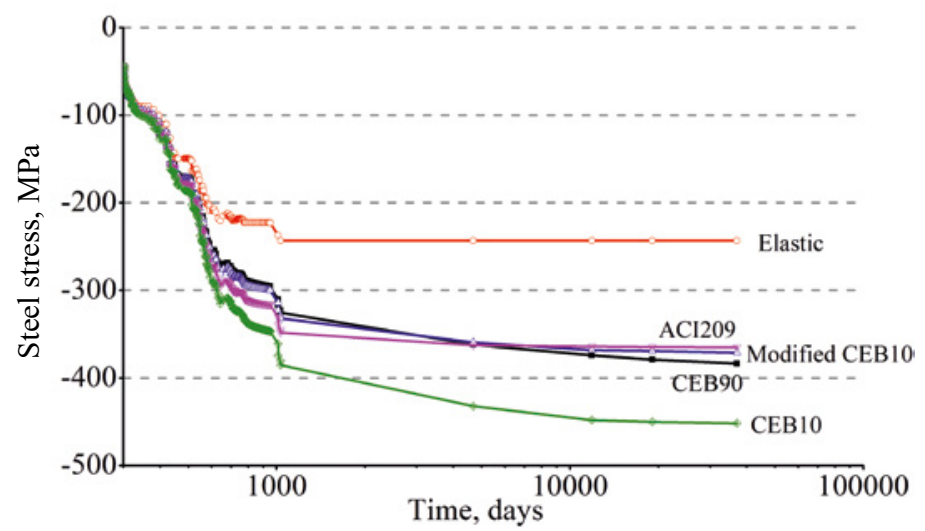

b) L/4-span cross section

Figure 10. Stresses of steel tube 
steel stress to be $2-22 \%$ larger than the results calculated by the modified CEB10 model (Wang, Zhao, Jia, \& Liao, 2019). After the bridge is finished, the concrete box girder suffers almost all the external loads even though the steel tube is in yielding, which indicates the bridge is still in a safe state. Table 4 summarises the statistical values of $M_{\text {СЕB }}$ for different models. Table 4 shows that the $M_{\text {CEB }}$ calculated by CEB90 model (CEB, 1993) and ACI209 model (ACI209 R-92,1992) is the minimum in 0 days to 1031 days and 1032 days to 37081 days, respectively. It means that not only the extremal shrinkage or creep strains but also the intermediate values in time $t$ are significant for evaluating the time-dependent behaviour of the concrete arch bridge (Al-Manaseer \& Prado, 2015).

Figure 11 is plotted to describe the core concrete stresses in No. 4 calculated by different creep models. The $M_{\mathrm{CEB}}$, as shown in Table 5 , are
Time-Dependent Behaviour Analysis of Long-Span Concrete Arch Bridge

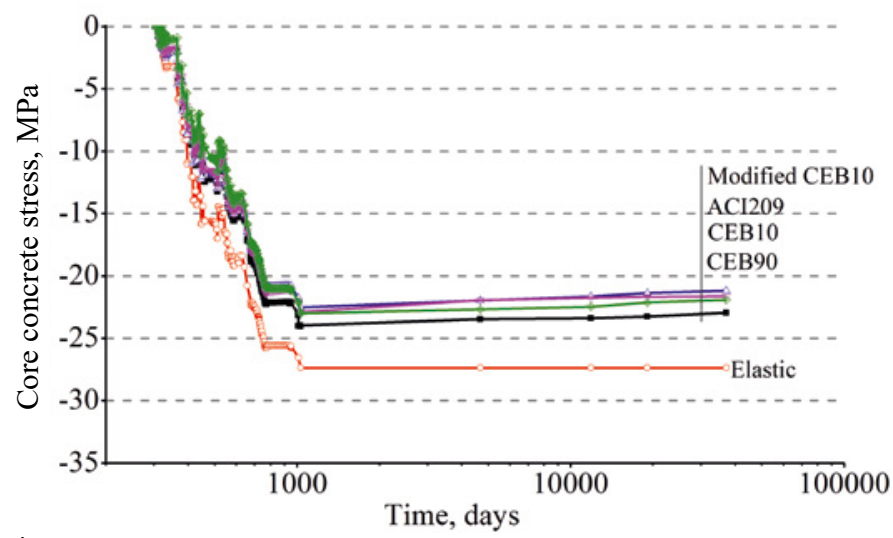

a) arch crown

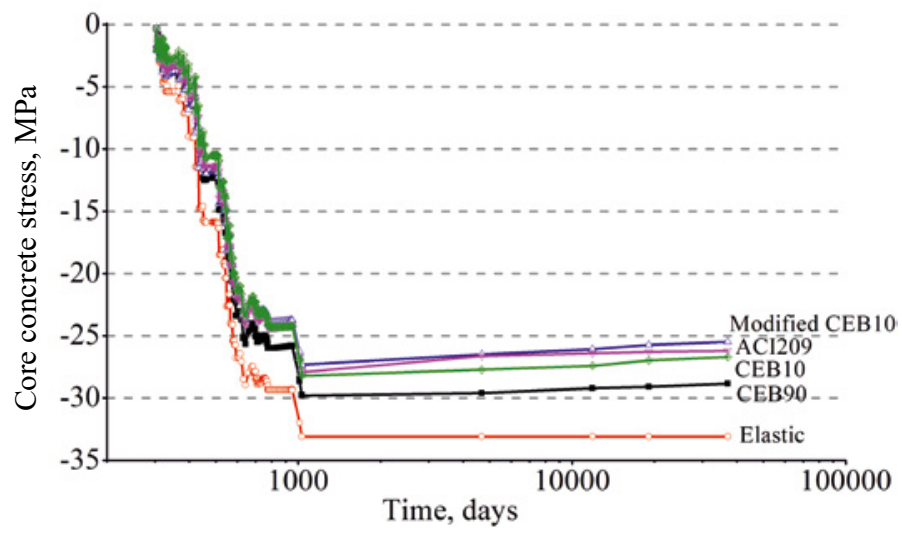

b) L/4-span cross section

Figure 11. Stresses of core concrete 
Table 5. Comparison of $M_{\mathrm{CEB}}$ results of stresses in core concrete

\begin{tabular}{lcccccccc}
\hline \multicolumn{1}{c}{ Location } & \multicolumn{3}{c}{ Arch crown } & \multicolumn{5}{c}{ L/4-span cross section } \\
\hline \multicolumn{1}{c}{ Models } & $\begin{array}{c}\text { Modified } \\
\text { CEB10 }\end{array}$ & ACI209 & CEB90 & CEB10 & $\begin{array}{c}\text { Modified } \\
\text { CEB10 }\end{array}$ & ACI209 & CEB90 & CEB10 \\
\hline $\begin{array}{l}M_{\text {CEB }} \text { in 0 days } \\
\text { to 1031 days }\end{array}$ & 0.7888 & 0.7654 & 0.8008 & 0.7162 & 0.7891 & 0.7631 & 0.8237 & 0.7350 \\
$\begin{array}{l}M_{\text {CEB }} \text { in 1032 days } \\
\text { to 37 081 days }\end{array}$ & 0.7943 & 0.8028 & 0.8553 & 0.8200 & 0.7925 & 0.8067 & 0.8858 & 0.8283 \\
\hline
\end{tabular}

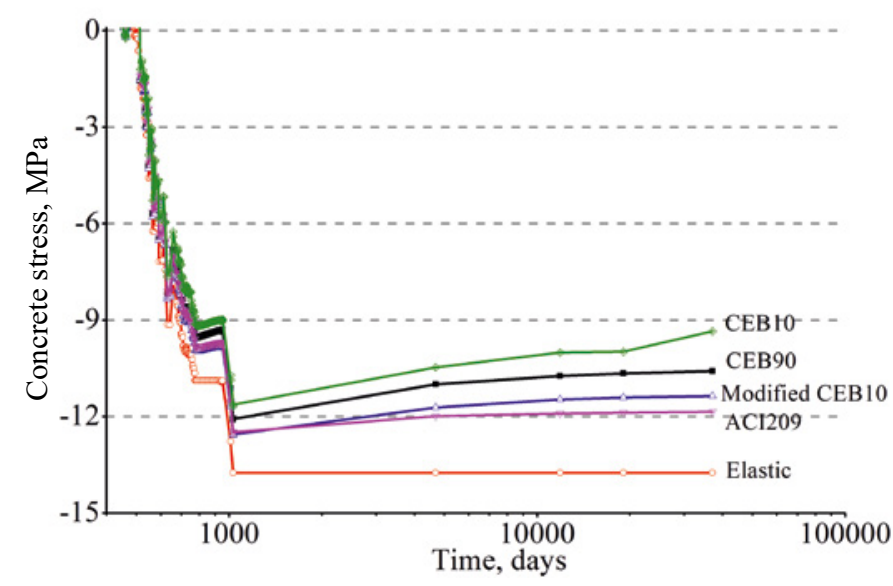

a) bottom plate

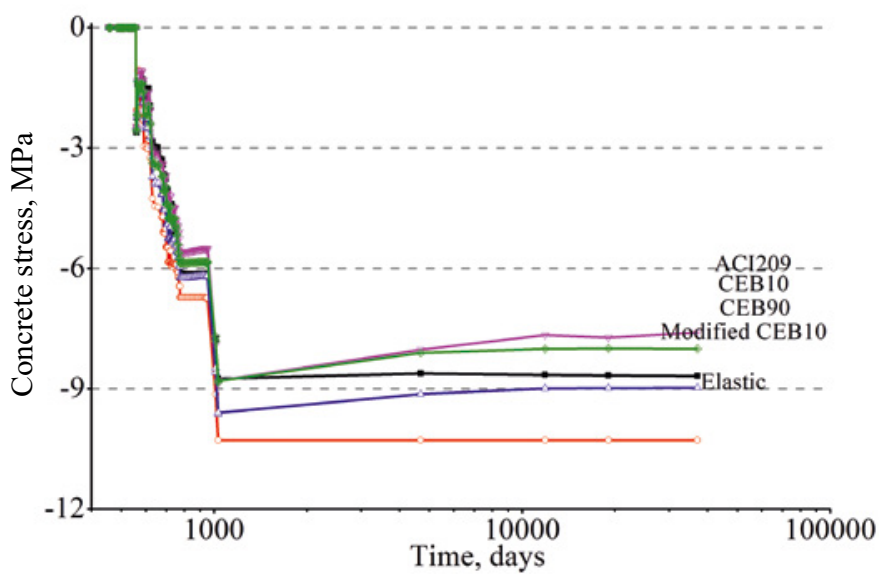

b) middle web

Figure 12. Stresses of surrounding concrete in L/4-span cross section 
less than 1.0 in all prediction models. The $M_{\mathrm{CEB}}$ values are significantly different from the database shown in Tables 3 and 4. From Figure 11 and Table 5, it is noted that the shrinkage and creep effect reduces the stress of core concrete in certain extents. The calculation results considering shrinkage and creep effect of concrete are higher than that without considering time-dependent effect. All the time-dependent models overestimated the core concrete stress except the modified CEB10 model (Wang, Zhao, Jia, \& Liao, 2019). Among all the prediction models, CEB90 model (CEB, 1993) underestimates the 100-year deflection by $18 \%$ compared with modified CEB10 model (Wang, Zhao, Jia, \& Liao, 2019), when the default parameter values are used. The 100-year stresses of core concrete estimated by other models are 3-18\% larger than the results calculated by the modified CEB10 model (Wang, Zhao, Jia, \& Liao, 2019).

Figure 12 displays the stresses of surrounding concrete influenced by different concrete creep models. The stresses of the bottom plate in the side box and web in the middle box of L/4-span section are shown in these graphs. Table 6 summarises the $M_{\text {СЕB }}$ results of stresses in the surrounding concrete. The $M_{\mathrm{CEB}}$ continues to decrease from Stage A to Stage B. It is different from the stress trend in core concrete, as shown in Table 5. The results calculated by considering the prediction models are much less than those without shrinkage and creep effects. Different creep models have a different effect on the stress in various part of the box-girder. In Stage B, the CEB10 model (CEB, 2012) has the minimum stress in the bottom plate. However, the ACI209 model (ACI209 R-92, 1992) has the minimum stress in the middle web. Compared with modified CEB10 model (Wang, Zhao, Jia, \& Liao, 2019), CEB10 model (CEB, 2012) and CEB90 model (CEB, 1993) overestimated the stress in 0 days to 1031 days. However, they underestimated the stress in 1032 days to 37081 days.
Time-Dependent Behaviour Analysis of Long-Span Concrete Arch Bridge

Table 6. Comparison of $M_{\mathrm{CEB}}$ results of stresses in the surrounding concrete

\begin{tabular}{ccccccccc}
\hline \multicolumn{1}{c}{ Location } & \multicolumn{3}{c}{ Bottom plate } & \multicolumn{5}{c}{ Middle web } \\
\hline \multicolumn{1}{c}{ Models } & $\begin{array}{c}\text { Modified } \\
\text { CEB10 }\end{array}$ & ACI209 & CEB90 & CEB10 & $\begin{array}{c}\text { Modified } \\
\text { CEB10 }\end{array}$ & ACI209 & CEB90 & CEB10 \\
\hline $\begin{array}{l}M_{\text {CEB }} \text { in 0 days } \\
\text { to 1031 days }\end{array}$ & 0.9036 & 0.8846 & 0.8669 & 0.8089 & 0.9161 & 0.8003 & 0.8587 & 0.8543 \\
$\begin{array}{l}M_{\text {CEB in 1032 days }} \\
\text { to 37 081 days }\end{array}$ & 0.8512 & 0.8746 & 0.8010 & 0.7485 & 0.8886 & 0.7744 & 0.8437 & 0.7959 \\
\hline
\end{tabular}




\section{Conclusions}

Based on the modified fib Model Code for Concrete Structures 2010 model and the Finite Element Model established on the computational program, the long-term behaviour of Beipanjiang Bridge was studied. The following conclusions were drawn from this study.

1. The long-term changed deformation of the arch crown after 100 years was $-98.5 \mathrm{~mm}$, which affect the safety of train operation. Compared with the modified fib Model Code for Concrete Structures 2010 model, the deformations calculated by ACI209 R-92 Prediction of Creep, Shrinkage and Temperature Effects in Concrete Structures model, 1990 CEB-FIP Model Code: Design Code model and fib Model Code for Concrete Structures 2010 model are $-38.94 \mathrm{~mm},-146.95 \mathrm{~mm}$, and $-171.47 \mathrm{~mm}$, respectively. A suitable prediction model for shrinkage and creep of concrete is the key to obtain the long-term deformation of the bridge. The modified fib Model Code for Concrete Structures 2010 model is more suitable to estimate the deformation in the present stage.

2. The shrinkage and creep causes stress redistribution between the steel tube and core concrete. The steel stress gradually increases, and the core concrete stress gradually decreases with time. The steel stress reaches its yield strength to some extent. If the yield of steel pipe is ignored, the stress of the steel tube in L/4-span section reach -451 MPa, when the fib Model Code for Concrete Structures 2010 model was used. Because of the stress redistribution, the core concrete stress in L/4-span section is $-25.5 \mathrm{MPa}$. All the traditional models overestimate the core concrete stress in 100 years after bridge construction.

3. The distribution of concrete stress is non-uniformly distributed in different parts of the box-girder. Stresses reach maximum after the completion of the bridge. Then, the stress of surrounding concrete continuous to decrease with time. Thus, the stress of the surrounding concrete is unimportant in controlling the design of this structure. The fib Model Code for Concrete Structures 2010 model, 1990 CEB-FIP Model Code: Design Code model overestimated the stress in the construction stage. However, they underestimated the stress in the finished stage.

The disadvantage of this paper is that the experimental data hardly verify the calculated long-term deformation of the arch crown. In addition, the concrete damage, corrosion effect and non-linear temperature stress were hardly considered. Those factors will be incorporated in future investigations. 


\section{Acknowledgements}

The China Railway Eryuan Engineering Group Co. Ltd. sponsors the experiment test in this work. The National Natural Science Foundation of China (51778531) and Shanxi Applied Basic Research Project (201801D221223) financially supports it.

\section{REFERENCES}

ACI209 R-92 Prediction of Creep, Shrinkage and Temperature Effects in Concrete Structures.

Al-Manaseer, A., \& Prado, A. (2015). Statistical comparisons of creep and shrinkage prediction models using RILEM and NU-ITI databases. ACI Materials Journal, 112(1), 125. https://doi.org/10.14359/51686982

Bažant, Z.P. \& Murphy, W. P. (1995). Creep and Shrinkage Prediction Model for Analysis and Design of Concrete Structures-Model B3. Materials and Structures 28:357-365. https://doi.org/10.1007/BF02473152.

Bažant, Z. P., Hubler, M. H., \& Yu, Q. (2011). Excessive creep deflections: An awakening. Concrete international, 33(8), 44-46.

Bažant, Z. P., Yu, Q., \& Li, G. H. (2012). Excessive long-time deflections of prestressed box girders. I: Record-span bridge in Palau and other paradigms. Journal of Structural Engineering, 138(6), 676-686. https://doi.org/10.1061/(ASCE)ST.1943-541X.0000487

Comite Euro-International du Beton (CEB) (1993). 1990 CEB-FIP Model Code 1990: Design Code

Comite Euro-International du Beton (CEB) (2012). fib Model Code for Concrete Structures 2010

Geng, Y., Wang, Y., Ranzi, G., \& Wu, X. (2013). Time-dependent analysis of long-span, concrete-filled steel tubular arch bridges. Journal of Bridge Engineering, 19(4), 04013019. https://doi.org/10.1061/(ASCE)BE.1943-5592.0000549

Goel, R., Kumar, R., \& Paul, D. K. (2007). Comparative study of various creep and shrinkage prediction models for concrete. Journal of materials in civil engineering, 19(3), 249-260. https://doi.org/10.1061/(ASCE)0899-1561(2007)19:3(249)

Hedegaard, B. D., French, C. E., \& Shield, C. K. (2016). Effects of cyclic temperature on the time-dependent behavior of posttensioned concrete bridges. Journal of Structural Engineering, 142(10), 04016062. https://doi.org/10.1061/(asce)st.1943-541x.0001538

Ma, K., Xiang, T., \& Xu, T. (2013). Probabilistic Analysis on Influence of Creep and Shrinkage on Time-Variant Stresses of High-Speed Railway Reinforced Concrete Arch Bridge, Journal of China Railway Society 35(9): 94-99. (in Chinese)
Time-Dependent Behaviour Analysis of Long-Span Concrete Arch Bridge 
Ma, K., Xiang, T. Y., Zhao, R. D., Xu, Y., \& Xie, H. 2012. Stochastic Analysis of Long-Term Deformation of Reinforced Concrete Arch Bridge for High-Speed Railways. China Civil Engineering Journal 45(11): 141-146.

Wang, Y. B., Zhao, R. D. Jia, Y., \& Liao P. (2019). Creep Characteristics of Concrete Used in Long-span Arch Bridge, The Baltic Journal of Road and Bridge Engineering 14(1): 18-36. https://doi.org/10.7250/bjrbe.2019-14.431

Wang, Y. F., Ma, Y. S., Han, B., \& Deng, S. Y. (2013). Temperature effect on creep behavior of CFST arch bridges. Journal of Bridge Engineering, 18(12), 1397-1405. https://doi.org/10.1061/(ASCE)BE.1943-5592.0000484

Wang, Y., Zhan, Y., \& Zhao, R. (2016). Analysis of thermal behavior on concrete box-girder arch bridges under convection and solar radiation. Advances in Structural Engineering, 19(7), 1043-1059. https://doi.org/10.1177/1369433216630829

Wendner, R., Tong, T., Strauss, A., \& Yu, Q. (2015). A case study on correlations of axial shortening and deflection with concrete creep asymptote in segmentally-erected prestressed box girders. Structure and Infrastructure Engineering, 11(12), 1672-1687.

https://doi.org/10.1080/15732479.2014.992442

Xie, H.Q. (2012). Study on Structural Type Selection and Mechanical Behaviors of Long-Span Railway Concrete Arch Bridge with Rigid Skeleton (Doctoral Dissertation, Southwest Jiaotong University) (In Chinese)

Yang, M. G., Cai, C. S., \& Chen, Y. (2015). Creep performance of concrete-filled steel tubular (CFST) columns and applications to a CFST arch bridge. Steel and Composite Structures, 19(1), 111-129.

https://doi.org/10.12989/scs.2015.19.1.111

Yu, Q., \& Li, G. H. (2012). Excessive long-time deflections of prestressed box girders. II: Numerical analysis and lessons learned. Journal of Structural Engineering, 138(6), 687-696.

https://doi.org/10.1061/(ASCE)ST.1943-541X.0000375

Zhang, J. (2015). A Unified Viscoelasto-Plastic Damage Model for Long-Term Performance of Prestressed Concrete Box Girders (Doctoral dissertation, University of Pittsburgh). 